\begin{abstract}
\begin{tabular}{llllllll} 
A & B & S & T & R & A & C & T \\
\hline
\end{tabular}
Introduction: Osteogenic effects of therapeutic fluoride have been reported; however, the impact of exposure to low level water fluoridation on bone density is not clear. We investigated the effect of long-term exposure to fluoridated water from growth to young adulthood on bone mineral density (BMD). Methods: BMD was measured in 24 healthy women from Regina (fluoride $0.1 \mathrm{mg} / \mathrm{L}$ ) and 33 from Saskatoon (fluoride $1.0 \mathrm{mg} / \mathrm{L}$ ), with no differences between groups for height, weight, lifestyle or dietary factors.

Results: Saskatoon women had significantly higher mean BMD at total anterior-posterior lumbar spine (APS) and estimated volumetric L3 (VLS), with no difference at total body (TB) or proximal femur (PF).

Conclusion: Exposure to water fluoridation during the growing years may have a positive impact on axial spine bone density in young women.
\end{abstract}

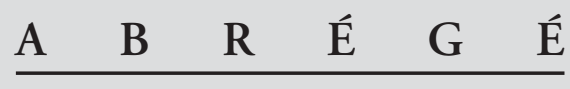

Introduction : Des effets ostéogénétiques du fluorure thérapeutique ont été signalés; cependant, l'influence d'une exposition à un faible niveau de fluoruration de l'eau sur la densité osseuse n'est pas claire. Nous avons étudié les effets d'une exposition de longue durée à l'eau fluorée sur la teneur minérale de l'os, pendant les années de croissance.

Méthodes : Chez 24 femmes en santé venant de Regina, on a mesuré la teneur minérale de l'os (fluorure $0,1 \mathrm{mg} / \mathrm{l}$ ) ainsi que chez 33 femmes venant de Saskatoon (fluorure 1,0 $\mathrm{mg} / \mathrm{l})$, sans noter aucune différence entre les groupes par rapport aux facteurs taille, poids, mode de vie ou régime.

Résultats : Les femmes de Saskatoon avaient une teneur minérale de l'os moyenne significativement plus élevée aux tomographies de la colonne lombaire antéropostérieures et de l'analyse volumétrique estimée à L3, sans aucune différence pour l'ensemble du corps ou le fémur proximal.

Conclusion : Une exposition à la fluoruration de l'eau pendant les années de croissance peut avoir un effet positif sur la densité osseuse rachidienne chez les jeunes femmes.

\title{
The Effect of Water Fluoridation on the Bone Mineral Density of Young Women
}

\author{
Cathy M. Arnold, MSc, ${ }^{1}$ Donald A. Bailey, PhD, ${ }^{2}$ Robert A. Faulkner, PhD, ${ }^{3}$ \\ Heather A. McKay, PhD, ${ }^{3}$ Robert G. McCulloch, $P h D^{4}$
}

Fluoride's ability to stimulate bone formation by increasing osteoblast activity has made it an attractive therapeutic agent to consider for the prevention and treatment of osteoporosis. ${ }^{1}$ Both high dose and slow release sodium fluoride has been found to increase trabecular bone mass and may decrease the frequency of vertebral fractures. $^{2,3}$ However, despite a modest increase in PF BMD* following fluoride therapy, there is no substantial evidence that fluoride decreases the incidence of hip fractures. ${ }^{1,2}$

Low levels of fluoride are ingested on a daily basis from food, water and dentifrices. It is estimated that the amount of fluoride ingested by an individual living in a Canadian community with fluoridated water of $1.0 \mathrm{mg} / \mathrm{L}$ is approximately 2.7 $\mathrm{mg} /$ day. ${ }^{4} \mathrm{It}$ is unknown if long-term exposure to this low level of fluoride has any effect on skeletal density.

There is no substantial evidence of an effect of long-term exposure to fluoridated water on hip fracture rates: the results are equivocal. ${ }^{5-7}$ Similarily, evidence supporting a positive effect of low level fluoride on axial BMD is also limited. There are reports that fluoride absorption is higher in

* See abstract for explanation of acronyms.

1. College of Physical Education and School of Physical Therapy, University of Saskatchewan

2. College of Physical Education, University of Saskatchewan and Human Movement Studies, University of Queensland

3. College of Physical Education, University of Saskatchewan

4. President's Office and Faculty of Physical Activity Studies, University of Regina

This study was funded by the Health Services Utilization and Research Commission.

Correspondence and reprint requests: C. Arnold,

School of Physical Therapy, University of Saskatchewan, Saskatoon, SK S7N 0W3, E-mail: arnoldc@sask.usask.ca greater trabecular bone sites such as the vertebral bodies as compared to more cortical bone sites. ${ }^{8}$ Kroger et al. ${ }^{9}$ found a small increase in axial BMD in older women exposed to water fluoridation of $1.0 \mathrm{mg} / \mathrm{L}$ compared to those exposed to a nonfluoridated water supply.

The amount of fluoride in bone correlates positively and exhibits a linear relationship with the amount of fluoride ingested from food and water. ${ }^{10}$ As well, fluoride has been found to absorb more rapidly in growing bone than in adult bone and appears to have its greatest impact on teeth during the growing years. ${ }^{4,11}$ It is possible that exposure to low level water fluoridation throughout the growing years would influence skeletal bone density in young adulthood, at the crucial time when peak bone density is achieved.

The cities of Regina and Saskatoon, only 200 miles apart, are of similar size, population and climatic conditions. Regina has never had supplemental fluoride in its water supply and has a natural occurring fluoride level of $<0.12$ to 0.15 $\mathrm{mg} / \mathrm{L}$ in its water. Saskatoon has had supplemental fluoride in its water since 1954, at a level of approximately $1.0 \mathrm{mg} / \mathrm{L}$. This level never exceeds $1.25 \mathrm{mg} / \mathrm{L}$ as ensured by a safety valve and does not go below $0.9 \mathrm{mg} / \mathrm{L}$ (Saskatoon Water Treatment Plant). The purpose of this study was to investigate the effect of long-term exposure to water fluoridation on BMD in young adult women. We hypothesized that BMD in the Saskatoon group would be higher than in the Regina group and that the greatest difference in BMD would be at the highly trabecular bone sites in the lumbar spine (APS and VLS) as compared to the PF. 


\section{METHODS}

Subjects were 57 females, aged 18 to 25 years, 24 volunteers from the University of Regina in Regina, and 33 from the University of Saskatchewan in Saskatoon. All subjects had not travelled outside of their resident city for longer than four years. Individuals with bone-affecting disorders, use of potential bone-affecting medications, long-term use of fluoride supplements, a history of amenorrhea (fewer than three menses per year, as defined by Armamento-Villareal et al. ${ }^{12}$ ), and those who were currently pregnant were excluded. This study was approved by the University of Saskatchewan Advisory Committee on Ethics in Human Experimentation.

\section{BMD measures}

BMD was measured using DXA (Hologic 2000, Hologic Waltham, MA) in array mode. ${ }^{13}$ All testing was performed from October 1994 to January 1995 at the Royal University Hospital in Saskatoon. A standard protocol was used for all scans. ${ }^{13}$ Subjects wore t-shirts and shorts for the testing procedure, removing all metal objects.

TB scans (Hologic software version 5.56A) were performed with the subject lying supine, positioned on the center line along the longitudinal axis of the table. The subject's hands were pronated and feet were taped together to immobilize the lower extremities. Bone-mineral-free lean mass and fat mass were also determined from the total body scans.

For the PF scan (Hologic software version 4.55A), the subject was supine with the hip internally rotated approximately $20^{\circ}$ and abducted. The foot was secured with a nylon strap against a lucite positioning wedge to secure this position.

APS and LS scans (Hologic software version 4.62A:1) were done with the subject supine with a foam-filled block supporting the femora in as vertical a position as possible. While the subject remained stationary, the c-arm was rotated to obtain the companion view of the LS.

Lumbar spine volume was estimated from the average width $(\mathrm{cm})$ of the vertebral body determined from the AP projection and the skeletal area scanned $\left(\mathrm{cm}^{2}\right)$ from the companion LS projection. The VLS $\left(\mathrm{g} / \mathrm{cm}^{3}\right.$, Hologic software version $4.55 \mathrm{~F}: 1$ ) was obtained by dividing the bone mineral content obtained from the LS by the estimated volume. Only L3 was used for VLS due to the increased error at L2 and L4 from overlying ribs close to L2 and the close proximity of the pelvis at L4. The LS scan eliminates the posterior spinous processes, allowing for an assessment of primarily trabecular bone. ${ }^{14}$

Short-term reproducibility in vivo with two repeat scans on 10 subjects ranged from a coefficient of variation $(\mathrm{CV})$ of $0.51 \%$ for TB, $1.1 \%$ for PF, $1.03 \%$ for APS, $2.11 \%$ for LS at L3 and $2.58 \%$ for VLS at L3.

\section{Lifestyle and dietary history questionnaire}

Subjects completed a comprehensive questionnaire evaluating various lifestyle, medical history and dietary factors. This questionnaire was developed based on the MEDOS questionnaire, ${ }^{15}$ an activity rating scale used by Sallis et al., ${ }^{16}$ a two-week recall of current physical activity, ${ }^{17}$ an estrogen exposure scoring criteria proposed by Armamento-Villareal et al. ${ }^{12}$ and a food frequency questionnaire used in previous studies at the University of Saskatchewan. ${ }^{18}$ Daily intake of calcium and vitamin $\mathrm{D}$ was determined by a nutritional assessment software package with 1988 Canadian Nutrition File information. Other questions on the use of bottled water and tap water intake were also included.

\section{Statistical methods}

SPSS for Windows was used for statistical analysis. Independent t-tests were performed to determine differences in height, weight, bone-mineral-free lean mass, fat mass, estrogen status, past and present physical activity level and current calcium intake between the two samples. Other lifestyle factors evaluated were: tap water consumption, family history of osteoporosis, smoking history, alcohol consumption, caffeine intake, milk history and Vitamin $\mathrm{D}$ intake. The two samples were very similar in these various lifestyle factors.

ANCOVA, with weight as the covariate, was used to compare BMD between the two samples. Weight was chosen as a covariate based on its significant, positive correlation with BMD ( $\underline{r}=0.43$ to 0.54 ). The only other variable that met the assumptions of a covariate was bonemineral-free lean mass. However, as bonemineral-free lean mass and body weight were highly correlated, body weight was chosen as the only covariate used in the analysis. An alpha level of 0.05 using a two-tailed test of significance was selected for all analyses.

\section{RESULTS}

There were no significant differences between the two samples for mean height, weight, bone-mineral-free lean mass, fat mass, daily calcium intake, or past or present physical activity level (Table I). The ANCOVA analysis found a significant difference between Regina and Saskatoon samples at the APS (L1 to L4, F $(54,1)=$ $7.33, \underline{\mathrm{p}}<0.05)$ and VLS $(\underline{\mathrm{F}}(53,1)=4.37$, $\mathrm{p}<0.05)$ but not at TB or PF. The effect size for the APS was $11.9 \%$ and $7.6 \%$ at VLS using eta ${ }^{2}$ (Table II).

\section{DISCUSSION}

The results of this study found that women raised in an environment with low level water fluoridation had significantly higher BMD values at the APS and VLS bone sites in the lumbar spine, but there were no significant differences between the two samples at the TB or PF.

Fluoride has two major effects on bone. First, fluoride substitutes for some of the hydroxyl ions in the mineralization phase forming fluorohydroxyapatite. This substitution increases bone crystallinity and decreases the ability of osteoclasts to resorb bone. Second, fluoride stimulates an increase in osteoblast number and activity. ${ }^{19}$ These two mechanisms support our hypothesis that long-term exposure to fluoride may result in increases in BMD. However, there continues to be debate in the literature regarding the role of both high doses of fluoride and exposure to low levels of fluoride on bone strength and fracture rates at various sites. ${ }^{1,3,5-7}$

The relative distribution of fluoride in the skeleton is greater in bone sites with increased biological activity such as cancel- 


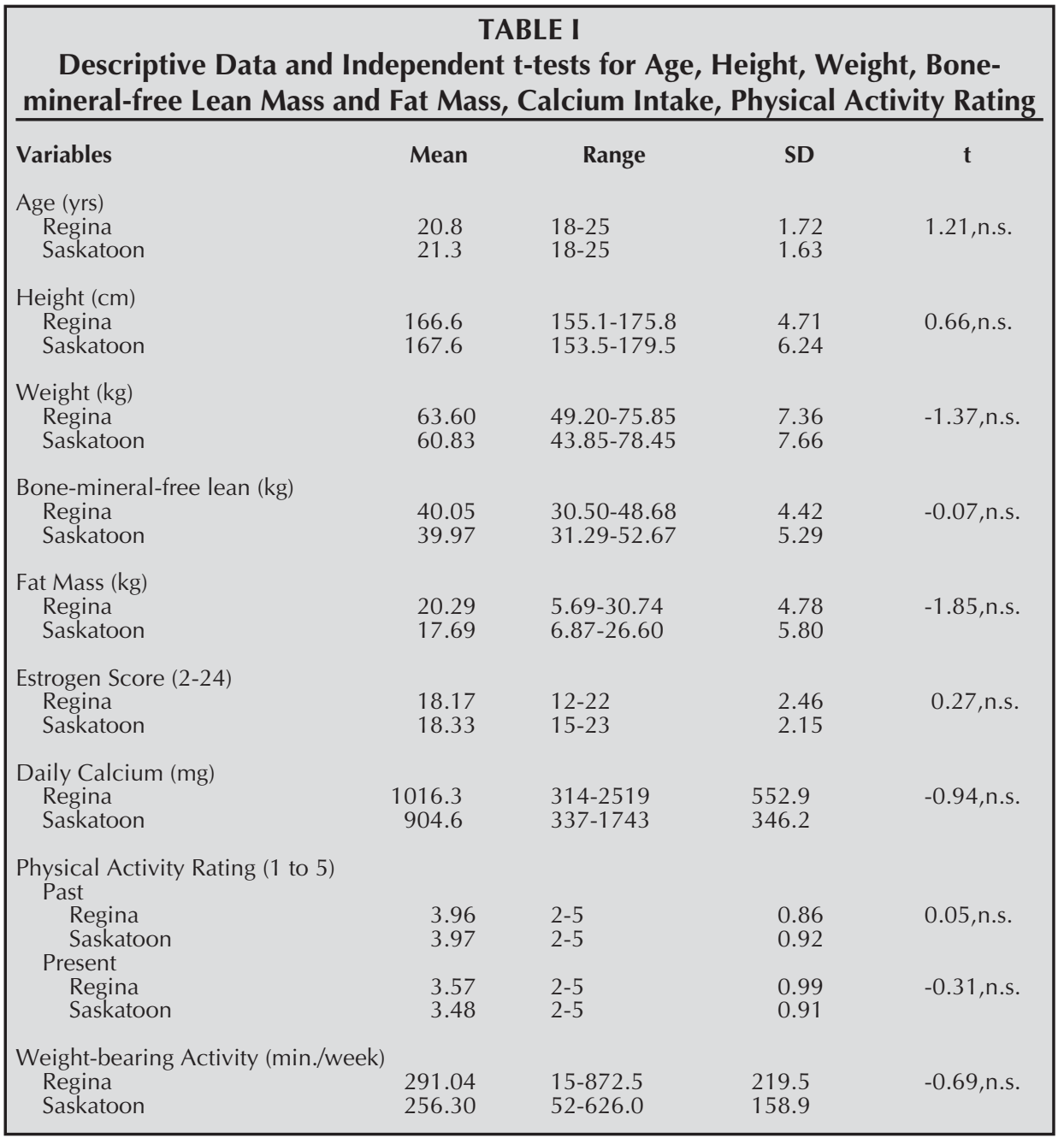

\begin{tabular}{|c|c|c|c|c|}
\hline \multicolumn{5}{|c|}{$\begin{array}{c}\text { TABLE II } \\
\text { Results of ANCOVA for APS, VLS, TB and PF }\end{array}$} \\
\hline Variable & \multicolumn{2}{|c|}{$\begin{array}{l}\text { Regina Saskatoon } \\
\text { Adjusted mean values } \\
\text { (unadjusted values } \pm S D \text { ) }\end{array}$} & $\mathbf{F}$ & $\begin{array}{c}\text { Effect Size } \\
\quad\left(\text { eta }^{2}\right)\end{array}$ \\
\hline $\begin{array}{l}\text { APS (Total) } \\
\left(\mathrm{g} / \mathrm{cm}^{2}\right)\end{array}$ & $\begin{array}{l}0.975 \\
(0.986 \pm .07)\end{array}$ & $\begin{array}{l}1.039 \\
(1.028 \pm .12)\end{array}$ & $7.33^{*}$ & 0.119 \\
\hline $\begin{array}{l}\text { VLS } \\
\left(\mathrm{g} / \mathrm{cm}^{3}\right)\end{array}$ & $\begin{array}{l}0.216 \\
(0.218 \pm .02)\end{array}$ & $\begin{array}{l}0.227 \\
(0.225 \pm .02)\end{array}$ & $4.37^{*}$ & 0.076 \\
\hline $\begin{array}{l}\text { TB } \\
\left(\mathrm{g} / \mathrm{cm}^{2}\right)\end{array}$ & $\begin{array}{l}1.044 \\
(1.051 \pm .06)\end{array}$ & $\begin{array}{l}1.073 \\
(1.065 \pm .08)\end{array}$ & 3.16 & 0.055 \\
\hline $\begin{array}{l}\mathrm{PF} \\
\left(\mathrm{g} / \mathrm{cm}^{2}\right)\end{array}$ & $\begin{array}{l}0.927 \\
(0.936 \pm .09)\end{array}$ & $\begin{array}{l}0.961 \\
(0.951 \pm .14)\end{array}$ & 1.30 & 0.024 \\
\hline
\end{tabular}

lous bone as compared to more cortical bone sites. ${ }^{8}$ The results of our study support this regional difference of fluoride's effect on bone. The two bone sites where exposure to fluoridated water resulted in greater $\mathrm{BMD}$ values were at the axial skeleton (APS and VLS). There was a $6.5 \%$ increase in mean APS BMD in the Saskatoon sample. Similar results have been found in a study of older women where there were significantly higher BMD values at the APS in women, aged 47-59, exposed to low level water fluoridation (3\% difference in BMD). ${ }^{9}$
It has been proposed that the volumetric estimate of bone density (VLS) may provide a more sensitive assessment of the more central trabecular bone of the vertebral body by eliminating the largely cortical posterior spines of the vertebrae. ${ }^{14}$ Also, because VLS is a volume estimate, it may provide a more accurate measure of the central vertebral bone content. Indeed, differences have been reported between areal BMD and VLS. Carter et al. ${ }^{20}$ found width-adjusted BMD values at the spine were not as dependent on height and weight as the more traditional areal BMD values. The significant difference between the Saskatoon and Regina samples for VLS values in our study support a positive association of exposure to water fluoridation on the BMD of the highly trabecular bone of the axial skeleton.

The nonsignificant finding at the PF supports the site-specific effect of fluoride on the axial skeleton. This would support other findings that there is likely no beneficial effect of long-term exposure to low levels of fluoride on hip fracture rates. ${ }^{7}$ Differences in TB BMD, although not significant, had an effect size of $5.5 \%$. This may suggest a small, general effect of low level fluoridation on the BMD in the total body. However, it is also possible that the amount of fluoride ingested from longterm exposure to water fluoridation is not enough to result in an increase in $\mathrm{TB}$ BMD. To our knowledge, this is the first study to evaluate the effect of fluoride on TB. Further investigation is needed to verify if there is any substantial effect of low level fluoride at the TB.

Limitations in this study are: a small sample size and already established differences in BMD from a number of other factors related to genetic, lifestyle or environmental influences. The small sample of volunteers from a university setting makes it difficult to generalize these results to the cities' populations. Further investigation in a larger sample of young women is necessary to justify the potential effect of exposure to water fluoridation on young women. Possible differences in BMD from other factors were addressed by a detailed evaluation of lifestyle, medical history and dietary habits which found that the two samples were very similar. The cities of 
Saskatoon and Regina, located only 200 miles apart, are very similar in population, demographics and sunlight exposure. There appeared to be no differences between the two groups that would explain differences in BMD other than exposure to different water supplies.

This study was unique in evaluating the effect of long-term exposure to low level fluoridation during the growing years. Ninety-five percent of the Saskatoon subjects and $83 \%$ of the Regina subjects had lived in their respective cities from birth until young adult age at the time of testing. Determining environmental influences on BMD during the growing years may be important for osteoporosis prevention as maximal peak bone density may be the best preventative measure against developing osteoporosis later in life. ${ }^{21}$ It is possible that exposure to fluoride would have its greatest osteogenic effect during the growing years primarily in highly trabecular bone sites such as the vertebrae of the lumbar spine.

\section{SUMMARY AND CONCLUSIONS}

The conclusions that can be drawn from this study are: 1) Fluoride absorbed from food and water during the growing years may have a positive impact on axial BMD in young female adults; and 2) Our results support the theory of site-specific absorption of fluoride in the highly trabecular bone in the lumbar vertebrae, with no apparent impact of ingestion of low levels of fluoride from the water supply on PF BMD.

\section{REFERENCES}

1. Melton III L. Fluoride in the prevention of osteoporosis and fractures. J Bone Miner Res 1990;5(1):S163-S167.

2. Riggs L. Treatment of osteoporosis with sodium fluoride or parathyroid hormone. Am J Med 1991;91(Supp.5B):37S-41S.

3. Pak C, Khashayer S, Adams-Huet B, et al. Treatment of postmenopausal osteoporosis with slow-release sodium fluoride. Ann Intern Med 1995;123(6):401-8.

4. Canadian Public Health Association. Criteria Document in Support of a Drinking Water Standard for Fluoride. (Final Report) Ottawa, ON: CPHA, 1979.

5. Simonen O, Laitinen O. Does fluoridation of drinking water prevent bone fragility and osteoporosis? Lancet 1985;24:432-33.

6. Danielson C, Lyon J, Egger M, Goodenough G. Hip fracture and fluoridation in Utah's elderly population. JAMA 1992;268(6):746-74.

7. Suarez-Almazor M, Flowerdew G, Saunders D, et al. The fluoridation of drinking water and hip fracture hospitalization rates in two Canadian communities. Am J Public Health 1993;83(5):689-93.

8. Gedalia I, Zipkin I. The Role of Fluoride in Bone Structure. St. Louis, Missouri: Warren H. Green Inc., 1973;6-7.

9. Kroger H, Alhava E, Honkanen R, et al. The effect of fluoridated drinking water on axial bone mineral density - a population based study. Bone Miner Res 1994;27:33-41.
10. Arnala I, Alhava E, Kauranen P. Effects of fluoride on bone in Finland. Acta Orthop Scand 1985;56:161-66.

11. Weidmann S, Weatherell J. Distribution in hard tissues. In: Fluorides and Human Health. World Health Organization Monographs (Serial No. 59) Geneva, Switzerland: World Health Organization, 1970;105-14.

12. Armamento-Villareal R, Villareal D, Avioli L, Civitelli R. Estrogen status and heredity are major determinants of pre-menopausal bone mass. J Clin Invest 1992;90:2464-71.

13. Hologic QDR Operater's Manual and User's Guide. Waltham, MA: Hologic Inc., 1991.

14. Peel N, Eastell R. Diagnostic value of estimated volumetric bone mineral density of the lumbar spine in osteoporosis. J Bone Miner Res 1994:9(3):317-20.

15. Dequeker J, Ranstam J, Valsson J, et al. The mediterranean osteoporosis (MEDOS) study questionnaire. Clin Rheumatol 1991;10(1):54-72.

16. Sallis J, Buono M, Roby J, et al. Seven day recall and other physical activity self reports in children and adolescents. Med Sci Sports Exerc 1993;25:99-108.

17. McCulloch R, Bailey D, Houston S, Dodd B. The effects of physical activity, calcium intake and selected lifestyle factors on bone mineral density in young women. CMAJ 1990;142(3):221-27.

18. McKay H, Whiting S, Faulkner R, Bailey D. The relationship of dietary calcium intake to lumbar spine bone mineral density maintenance in premenopausal women. Bone 1993;16:S191.

19. Priest N, Van De Vyver F. Trace Metals and Fluoride in Bones and Teeth. Boca Raton, Florida: CRC Press, 1990.

20. Carter D, Bouxsein M, Marcus R. New approaches for interpreting projected bone densitometry data. J Bone Miner Res 1992;7:137-45.

21. Stevenson J. Pathogenesis, prevention and treatment of osteoporosis. Obstet Gynecol 1990;75(4Suppl.):36S-41S.

Received: February 14, 1997

Accepted: June 14, 1997

\section{Anti-tuberculosis Drug Resistance in the World}

\section{The WHO/IUATLD Global Project on Anti-tuberculosis Drug Resistance Surveillance}

$$
\text { 1997, } 227 \text { pages (English) }
$$

Order \#1930117

$\$ 31.50$

This book describes the design and findings of a major study conducted to measure the prevalence of anti-tuberculosis drug resistance throughout the world. Jointly organized by WHO and the International Union Against Tuberculosis and Lung Disease (IUATLD), the study was initiated in response to growing concern about the problem of drug resistance and its potentially dramatic impact on the epidemiology and control of TB. Apart from documenting the true magnitude of the problem, the study aimed to determine the impact of specific treatment policies on the level of drug resistance and thus provide lessons for effective TB control.

The study used a rigorous methodology and innovative quality control to achieve uniformly high-quality data unprecedented in their accuracy and international comparability. Thirty-five countries from five continents took part in the study, and surveys were conducted on over 50,000 tuberculosis cases sampled from areas representing $20 \%$ of the world's population.

\section{Available from / Disponible au}

CPHA Health Resources Centre / Centre de documentation sur la santé de l'ACSP 400-1565 avenue Carling Avenue, Ottawa, ON, K1Z 8R1 